\title{
Weight Gain Composition in Preterm Infants with Dual Energy X-Ray Absorptiometry
}

\author{
CATHERINE PIELTAIN, MARIO DE CURTIS, PAUL GÉRARD, AND JACQUES RIGO
}

Department of Pediatrics, Division of Neonatology, University of Liège, CHR Citadelle, B-4000 Liège, Belgium [C.P., M.D.C., J.R.]; Istituto Materno-Infantile, University of Palermo, I-90142 Palermo, Italy

[M.D.C.]; and Institut de Mathématique, University of Liège, B-4000 Liège, Belgium [P.G.]

\section{ABSTRACT}

Whole body composition was investigated using dual energy $\mathrm{x}$-ray absorptiometry in 54 healthy preterm infants, birth weight $<1750 \mathrm{~g}$, who were fed fortified human milk $(n=20)$ and preterm formula $(n=34)$ when full enteral feeding was attained and then again $3 \mathrm{wk}$ later at around the time of discharge. Weight gain composition was calculated from the difference between the earlier and later measurement. The minimal detectable changes in whole body composition over time according to the variance of the population (within groups of 20 infants) and the minimal detectable changes according to the dietary intervention (between two groups of 20 infants) were determined at $5 \%$ significance and $80 \%$ power. Whole body composition was similar in the two groups at the initial measurement, but all the measured variables differed at the time of the second measurement. Formula-fed infants showed a greater weight gain (19.9 \pm 3.2 versus $\left.15.9 \pm 2.2 \mathrm{~g} \cdot \mathrm{kg}^{-1} \cdot \mathrm{d}^{-1}, p<0.05\right)$, fat mass deposition $(5.1 \pm 1.9$ versus $\left.3.3 \pm 1.3 \mathrm{~g} \cdot \mathrm{kg}^{-1} \cdot \mathrm{d}^{-1}, p<0.05\right)$, bone mineral content gain (289 \pm 99 versus $\left.214 \pm 64 \mathrm{mg} \cdot \mathrm{kg}^{-1} \cdot \mathrm{d}^{-1}, p<0.05\right)$, and increase in bone area $\left(1.6 \pm 0.4\right.$ versus $\left.1.3 \pm 0.3 \mathrm{~cm}^{2} \cdot \mathrm{kg}^{-1} \cdot \mathrm{d}^{-1}, p<0.05\right)$ compared with the fortified human milk group. From these data, a minimal increase from the first measurement of $111 \mathrm{~g}$ lean body mass, $68 \mathrm{~g}$ fat mass, and $3.1 \mathrm{~g}$ bone mineral content is needed to be detectable in a longitudinal study that includes 20 infants. For significance between two groups of 20 infants around the time of discharge, dietary intervention needs to achieve minimal differences of $160 \mathrm{~g}$ lean body mass, $86 \mathrm{~g}$ fat mass, and $4.1 \mathrm{~g}$ bone mineral content. With respect to weight gain composition, the minimal differences required to reach significance are $2.1 \mathrm{~g} \cdot \mathrm{kg}^{-1} \cdot \mathrm{d}^{-1}$ for gain in lean body mass, $1.2 \mathrm{~g} \cdot \mathrm{kg}^{-1} \cdot \mathrm{d}^{-1}$ for gain in fat mass, and 76 $\mathrm{mg} \cdot \mathrm{kg}^{-1} \cdot \mathrm{d}^{-1}$ for gain in bone mineral content. We conclude that dual energy $\mathrm{x}$-ray absorptiometry allows evaluation of the effects of dietary intervention on whole body and weight gain composition in preterm infants during the first weeks of life. (Pediatr Res 49: 120-124, 2001)

\section{Abbreviations}

BMDI, bone mineral density index

DXA, dual energy x-ray absorptiometry

FHM, fortified human milk

PTF, preterm formula
In recent decades, with the progressive increase in the survival of preterm infants, there has been increased interest in their nutritional evaluation in the light of knowledge that adequate feeding in the early weeks of life influences shortand long-term development $(1,2)$. Measurement of body composition is of fundamental importance in the nutritional care for preterm infants, and many techniques have been developed (3-7). Metabolic balances associated with indirect calorimetry allowed the composition of weight gain in preterm infants to be defined $(8,9)$. The complexity of such techniques and the fact that weight gain composition could only be obtained over a

Received April 1, 1999; accepted April 2, 2000.

Correspondence and reprint requests: Jacques Rigo, M.D., Neonatal Unit, University of Liège, CHR Citadelle, Bld du 12e de Ligne 1, 4000 Liège, Belgium.

Supported in part by a Bristol-Myers Squibb/Mead-Johnson Grant and a Wyeth-Ayerst Research Grant.

Presented in part at the European Society for Pediatric Research Meeting in Lyon, September 1-6, 1996 and at the European Society for Pediatric Research Meeting in Copenhagen, June 26-29, 1999. short period of time resulted in the need for a new and reliable method of study. DXA has emerged as an accurate, precise, and reproducible technique for measuring whole body composition in vivo in humans. Determination of lean body mass, fat mass, bone area, and bone mineral content can all be done using DXA (10-14). Reference values of body composition in preterm and term infants at birth have been reported $(11,12)$. Our aim in the present study was to measure body composition and weight gain composition by DXA in preterm infants fed exclusively on either FHM or PTF and to evaluate the sensitivity of the study design by using DXA to measure changes in whole body and weight gain composition in preterm infants during the first weeks of life.

\section{METHODS}

Healthy preterm infants without any clinical problems were studied longitudinally. An initial study was performed after full enteral feeding had been achieved and the infant's clinical 
condition allowed us to undertake the DXA examination. A second DXA measurement was done at the time of discharge. Additional inclusion criteria for the present study were a body weight at the first evaluation below $1750 \mathrm{~g}$ and a weight gain of more than $500 \mathrm{~g}$ between the two evaluations.

At the time of evaluation, all infants were weighed naked on an electronic baby scale (SECA, model 727, Hamburg, Germany) to the nearest $5 \mathrm{~g}$. Crown-heel length (on an infant length board to the next succeeding $0.1 \mathrm{~cm}$ ) and head circumference (using a paper insertion tape to the next succeeding millimeter) were also determined. All measurements were performed by one of us (C.P.).

The present study was approved by the Human Ethics Committee of the University of Liege. Informed parental consent was obtained.

Total and partial parenteral nutrition was used from admission until an adequate volume of oral feeding had been achieved. Enteral nutrition with human milk was initiated as soon as possible between the first and fifth day of life according to the infant's clinical condition. Supplemental parenteral nutrition was withdrawn after an oral intake of $100-120 \mathrm{~mL} \cdot \mathrm{kg}^{-}$ $1 \cdot \mathrm{d}^{-1}$ had been reached. When full oral diet had been attained, the infants were either continued on FHM or were weaned to PTF according to the mother's choice. Mother's own human milk was supplemented with banked human milk as available and by up to 3 to $4 \%$ with two similar fortifiers: Eoprotin (Milupa) or BMF (Nutricia). The formula-fed infants received PTF Nenatal (Nutricia), Prematil (Milupa), or Premie (Wyeth). A record of feed intake was kept during the entire study to estimate supply of nutrients.

Body composition was measured with the QDR 2000 bone densitometer (Hologic Inc, Waltham, MA, U.S.A.). Scans were analyzed using infant whole body software V5.65P supplied by the manufacturer $(11,15)$. The principle of the DXA procedure is described elsewhere $(10-13,16)$. Quality control scans were performed daily on an anthropometric spine phantom supplied by the manufacturer. The mean coefficients of variation for bone mineral content, bone area, and bone mineral density measurements over a period of 3 y $(n=486)$ were less than $0.5 \%$. For whole body measurements, we used an infant table pad that filters the lower energy beam; this improves system linearity in small subjects and reduces the radiation dose (11, $12,15)$. Whole body composition data analysis provides measurements of bone mineral density $(\mathrm{g})$, bone area $\left(\mathrm{cm}^{2}\right)$, fat mass $(\mathrm{g})$, and lean body mass $(\mathrm{g})$, whereas the software calculated body weight and bone mineral content (15). In this study, DXA fat mass and lean body mass were recalculated on the basis of our validation study in piglets; these values have already been used to obtain reference values in preterm and term infants (12).

Bone mineral density, calculated as bone mineral content per unit area of bone, is highly dependent on anthropometric variables. Therefore, we prefer to use bone mineral content adjusted for bone area (17) or BMDI [bone mineral content $\left.(\mathrm{mg}) /\left(\text { bone area }\left(\mathrm{cm}^{2}\right)\right)^{1.7}\right]$, which enables us to obtain a density index independently of anthropometric variables. We have reported measurements made in preterm and term infants at birth $(18,19)$.
During the DXA measurement, infants were placed in the supine position on an infant table pad. They were scanned only once. No sedation was given. To avoid movement artifacts, defective scans-that is, those showing discontinuity of the lateral edges of skeletal bones on the video monitor-were discarded according to Koo et al. (11).

From the difference in body composition values between the second and the first examinations, we determined body weight gain and weight gain composition. Increases in lean body mass, fat mass, and bone mineral content were expressed per $\mathrm{kg} / \mathrm{d}$ and compared in infants fed FHM and PTF.

The data were analyzed using PC statistical software (Statistica, version for Window 5.0, 1995, Statsoft, Tulsa, OK, U.S.A.). Anthropometric variables parameters in the two groups and longitudinal data in each group were compared using unpaired and paired $t$ test. Data of body and weight gain composition in the FHM and PTF groups were compared using ANOVA, taking groups as the independent variable and sex, birth weight, gestational age, and postnatal age as covariates. Differences were considered significant at $p<0.05$. Values are expressed as mean with $\mathrm{SD}(\mathrm{M} \pm 1 \mathrm{SD})$. Anthropometric and DXA values were also compared with intrauterine reference values $(12,20)$. For those comparisons, $Z$ scores were determined as $(X-M) / S$, where $X=$ individual anthropometric and DXA values, $\mathrm{M}=$ mean value of the reference according to gestational age (20) and body weight (12), and S = SD of the reference.

From the mean and SD of the differences between the values of body weight, lean body mass, fat mass, bone mineral content, and bone area at the two determinations, the minimal significant longitudinal changes were calculated for a sample size of 20 infants. The minimal significant difference according to dietary intervention for body composition and weight gain composition variables at the end of the study was also evaluated for a sample size of 20 infants in each group. The calculations were carried out for a $5 \%$ level of significance $(\alpha$ risk $=0.05)$ and $80 \%$ power $(\beta$ risk $=0.20)(21)$.

\section{RESULTS}

Fifty-four healthy preterm infants (29 female and 25 male) were included in the study. Forty-five were appropriately grown for gestational age (20). Twenty infants were fed FHM (FHM group) and thirty-four received a PTF (PTF group). In the two groups, anthropometric variables (Table 1) and whole body composition (Table 2) were similar at birth and at the start of the nutrition study period, performed at a mean age of $21 \mathrm{~d}$ (group FHM) and $22 \mathrm{~d}$ (group PTF). Over the whole period of study, milk intake was significantly higher in the FHM group than in the PTF group $(165 \pm 11$ versus $147 \pm 11$ $\left.\mathrm{mL} \cdot \mathrm{kg}^{-1} \cdot \mathrm{d}^{-1}, p<0.0001\right)$.

At the time of the second measurement, body weight was significantly lower in preterm infants fed FHM than in those fed PTF, whereas body length and head circumference were similar in the two groups (Table 1). Lean body mass, fat mass, bone mineral content, and bone area were significantly lower in preterm infants fed FHM than in those fed PTF (Table 2). Lean body mass and fat mass were, respectively, 89.2 and $9.5 \%$ of 
Table 1. Anthropometric characteristics of FHM- and PTF-fed infants

\begin{tabular}{lcc}
\hline & FHM $(n=20)$ & PTF $(n=34)$ \\
\hline At birth & $7 \mathrm{M} / 13 \mathrm{~F}$ & $18 \mathrm{M} / 16 \mathrm{~F}$ \\
$\quad$ Sex & $5 \mathrm{SGA} / 15 \mathrm{AGA}$ & $4 \mathrm{SGA} / 30 \mathrm{AGA}$ \\
IUG status & $1298 \pm 317$ & $1269 \pm 261$ \\
Weight $(\mathrm{g})$ & $38.7 \pm 3.4$ & $38.6 \pm 2.8$ \\
Length $(\mathrm{cm})$ & $27.8 \pm 2.1$ & $27.5 \pm 2.0$ \\
Head circumference $(\mathrm{cm})$ & $31 \pm 2$ & $30 \pm 2$ \\
Gestational age $(\mathrm{wk})$ & & \\
At $1^{\circ}$ examination & $21 \pm 11$ & $22 \pm 14$ \\
Age $(\mathrm{d})$ & $1482 \pm 164$ & $1448 \pm 185$ \\
Weight $(\mathrm{g})$ & $40.4 \pm 2.1$ & $40.3 \pm 1.9$ \\
Length $(\mathrm{cm})$ & $29.4 \pm 1.4$ & $29.2 \pm 1.3$ \\
Head circumference $(\mathrm{cm})$ & & \\
At $2^{\circ}$ examination & $44 \pm 12$ & $47 \pm 16$ \\
Age $(\mathrm{d})$ & $2112 \pm 166$ & $2362 \pm 231^{*}$ \\
Weight $(\mathrm{g})$ & $43.6 \pm 1.5$ & $44.1 \pm 1.5$ \\
Length $(\mathrm{cm})$ & $32.3 \pm 1.4$ & $33.0 \pm 0.9$ \\
Head circumference $(\mathrm{cm})$ & & \\
\hline
\end{tabular}

$* p<0.05$ vs FHM-fed infants.

IUG indicates intrauterine growth; SGA, small for gestational age; AGA, appropriate for gestational age.

body weight in the FHM group and 85.5 and $13.2 \%$ in the PTF group, whereas bone mineral content accounted for $1.3 \%$ in both groups. BMDI was similar but decreased significantly from the first to the second evaluation in the two groups $(p<$ 0.001 ). At the end of the study, lean body mass, fat mass, and bone area were in the range of the reference values related to body weight and determined in preterm and term infants at birth (12). By contrast, bone mineral content related to body weight or to bone area, as well as BMDI, were similar in the two groups, although significantly lower than the reference value (Fig. 1).

During the study, weight gain was lower in infants fed FHM $\left(15.9 \pm 2.2 \mathrm{~g}^{\mathrm{kg}} \mathrm{kg}^{-1} \cdot \mathrm{d}^{-1}\right)$ than in those fed PTF $(19.9 \pm 3.2$ $\left.\mathrm{g} \cdot \mathrm{kg}^{-1} \cdot \mathrm{d}^{-1}\right)(p<0.001)$, whereas length gain and head circumference were not significantly different $(p=0.45$ and $p=0.07$, respectively). The gains in lean body mass, fat mass, bone mineral content, and bone area were significantly lower in infants fed FHM than in those fed PTF (Table 2). The contribution of fat mass to weight gain was significantly less in the FHM group $(20.9 \pm 7.3$ versus $25.8 \pm 7.3 \%, p<0.05)$.

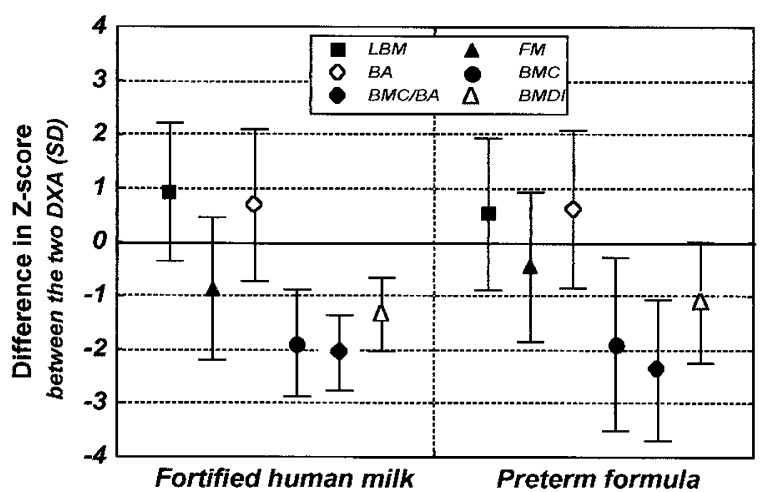

Figure 1. Body composition change in $Z$ score between the two DXA. $Z$ scores were related to our reference values determined in preterm and term infants at birth $(12,19)$.
Table 2. Body composition and weight gain composition in preterm infants fed FHM or PTF

\begin{tabular}{|c|c|c|}
\hline & $\operatorname{FHM}(n=20)$ & $\operatorname{PTF}(n=34)$ \\
\hline \multicolumn{3}{|l|}{ At $1^{\circ}$ examination } \\
\hline LBM $(g)$ & $1391 \pm 147$ & $1355 \pm 147$ \\
\hline $\mathrm{FM}(\mathrm{g})$ & $71 \pm 35$ & $75.4 \pm 55.5$ \\
\hline FM $(\%)$ & $4.7 \pm 2.3$ & $4.9 \pm 2.5$ \\
\hline $\mathrm{BMC}(\mathrm{g})$ & $19.5 \pm 3.1$ & $18.0 \pm 3.5$ \\
\hline $\mathrm{BA}\left(\mathrm{cm}^{2}\right)$ & $157 \pm 17$ & $153 \pm 18$ \\
\hline BMDI & $3.4 \pm 0.3$ & $3.3 \pm 0.3$ \\
\hline \multicolumn{3}{|l|}{ At $2^{\circ}$ examination } \\
\hline LBM $(\mathrm{g})$ & $1883 \pm 161 *$ & $2015 \pm 190 *, \dagger$ \\
\hline FM $(\mathrm{g})$ & $200 \pm 54^{*}$ & $315 \pm 122 *, \dagger$ \\
\hline FM $(\%)$ & $9.5 \pm 2.6$ & $13.2 \pm 4.5^{*}, \dagger$ \\
\hline $\mathrm{BMC}(\mathrm{g})$ & $28.0 \pm 3.5^{*}$ & $31.3 \pm 5.4^{*}, \dagger$ \\
\hline $\mathrm{BA}\left(\mathrm{cm}^{2}\right)$ & $210 \pm 15^{*}$ & $225 \pm 22 * \dagger$ \\
\hline BMDI & $3.0 \pm 0.2 *$ & $3.0 \pm 0.3^{*}$ \\
\hline \multicolumn{3}{|l|}{ Between examinations } \\
\hline Weight gain $(\mathrm{g} / \mathrm{kg} / \mathrm{d})$ & $15.9 \pm 2.2$ & $19.9 \pm 3.2 \dagger$ \\
\hline Length $(\mathrm{cm} / \mathrm{wk})$ & $1.0 \pm 0.3$ & $1.1 \pm 0.3$ \\
\hline Head circumference $(\mathrm{cm} / \mathrm{wk})$ & $0.9 \pm 0.2$ & $1.1 \pm 0.3$ \\
\hline $\operatorname{LBM}(\mathrm{g} / \mathrm{kg} / \mathrm{d})$ & $12.4 \pm 1.9$ & $14.5 \pm 3.5 \dagger$ \\
\hline $\mathrm{FM}(\mathrm{g} / \mathrm{kg} / \mathrm{d})$ & $3.3 \pm 1.3$ & $5.1 \pm 1.9 \dagger$ \\
\hline FM gain $(\%)$ & $4.8 \pm 2.3$ & $8.3 \pm 2.5 \dagger$ \\
\hline $\mathrm{BA}\left(\mathrm{cm}^{2} / \mathrm{kg} / \mathrm{d}\right)$ & $1.3 \pm 0.3$ & $1.6 \pm 0.4 \dagger$ \\
\hline $\mathrm{BMC}(\mathrm{mg} / \mathrm{kg} / \mathrm{d})$ & $214 \pm 64$ & $289 \pm 99 \dagger$ \\
\hline
\end{tabular}

$\mathrm{BA}$, bone area; $\mathrm{BMC}$, bone mineral content; $\mathrm{BMDI}=\mathrm{BMC}(\mathrm{mg}) /$ $\left(\mathrm{BA}\left(\mathrm{cm}^{2}\right)\right)^{1.71} ; \mathrm{FM}$, fat mass; LBM, lean body mass.

$* p<0.05 v s 1^{\circ}$ examination.

$\dagger p<0.05$ vs FHM-fed infants.

At the $5 \%$ level of significance and $80 \%$ power, the minimal detectable changes over time within a group of 20 infants weighing approximately $1500 \mathrm{~g}$ represented $154 \mathrm{~g}(10.5 \%)$ for body weight, $111 \mathrm{~g}(8.1 \%)$ for lean body mass, $13.9 \mathrm{~cm}^{2}$ (9.0\%) for bone area, $3.1 \mathrm{~g} \mathrm{(16.7 \% )}$ for bone mineral content, and $68 \mathrm{~g}$ for fat mass $(91.9 \%$ of the extremely low fat mass content at the first evaluation in Table 3). As fat mass represented on average 20.9 and $25.8 \%$ of the weight gain, respectively, in the FHM and PTF groups, the minimal total body weight gain necessary to obtain a significant difference from the first examination in all the whole body composition variables in a cohort of 20 preterm infants can be estimated as $325 \mathrm{~g}(68 \mathrm{~g} / 0.209)$ in the FHM group and $264 \mathrm{~g}(68 \mathrm{~g} / 0.258)$ in the PTF group, corresponding to an interval of 12 and $8 \mathrm{~d}$ in a longitudinal study.

At the time of discharge, the minimal detectable differences in body composition between groups when comparing the dietary intervention (Table 3 ) represented around $8 \%$ for body weight $(182 \mathrm{~g})$, lean body mass $(160 \mathrm{~g})$, and bone area (17.1 $\left.\mathrm{cm}^{2}\right), 13.6 \%$ for bone mineral content $(4.1 \mathrm{~g})$, and $31.6 \%$ for fat mass $(86 \mathrm{~g})$. For weight gain composition calculated between the two DXA, the minimal detectable difference was, respectively, $2.3 \mathrm{~g} \cdot \mathrm{kg}^{-1} \cdot \mathrm{d}^{-1}$ for body weight, $2.1 \mathrm{~g} \cdot \mathrm{kg}^{-1} \cdot \mathrm{d}^{-1}$ for lean body mass, $1.2 \mathrm{~g} \cdot \mathrm{kg}^{-1} \cdot \mathrm{d}^{-1}$ for fat mass, $76 \mathrm{mg} \cdot \mathrm{kg}^{-1} \cdot \mathrm{d}^{-1}$ for bone mineral content, and $0.32 \mathrm{~cm}^{2} \cdot \mathrm{kg}^{-1} \cdot \mathrm{d}^{-1}$ for bone area.

\section{DISCUSSION}

These data represent some of the first published values on early weight gain composition obtained with DXA in preterm infants in relation to the type of feeding regimen $(13,18,22$, 
Table 3. Minimal significant difference of whole body composition and weight gain composition detectable with DXA in preterm infants during the first weeks of life

\begin{tabular}{|c|c|c|c|c|c|c|}
\hline Gain & $\begin{array}{c}\text { Within groups } \\
n=20\end{array}$ & $\%(*)$ & $\begin{array}{l}\text { Between groups } \\
n=20 \text { /group }\end{array}$ & $\%(\dagger)$ & $\begin{array}{l}\text { Between groups } \\
n=20 \text { /group }\end{array}$ & $\%(+)$ \\
\hline Body weight & $154 \mathrm{~g}$ & 10.5 & $182 \mathrm{~g}$ & 8.0 & $2.3 \mathrm{~g} / \mathrm{kg} / \mathrm{d}$ & 12.5 \\
\hline LBM & $111 \mathrm{~g}$ & 8.1 & $160 \mathrm{~g}$ & 8.1 & $2.1 \mathrm{~g} / \mathrm{kg} / \mathrm{d}$ & 15.3 \\
\hline FM & $68 \mathrm{~g}$ & 91.9 & $86 \mathrm{~g}$ & 31.6 & $1.2 \mathrm{~g} / \mathrm{kg} / \mathrm{d}$ & 27.0 \\
\hline $\mathrm{BMC}$ & $3.1 \mathrm{~g}$ & 16.7 & $4.1 \mathrm{~g}$ & 13.6 & $76 \mathrm{mg} / \mathrm{kg} / \mathrm{d}$ & 29.1 \\
\hline $\mathrm{BA}$ & $13.9 \mathrm{~cm}^{2}$ & 9.0 & $17.1 \mathrm{~cm}^{2}$ & 7.8 & $0.32 \mathrm{~cm}^{2} / \mathrm{kg} / \mathrm{d}$ & 21.9 \\
\hline
\end{tabular}

* $\%$ of the body composition at first DXA.

$\dagger \%$ of the body composition at second DXA.

$+\%$ of the mean weight gain composition values.

23). We designed our present study on the basis of our previous results obtained with metabolic balances and indirect calorimetry, which showed significant differences in weight gain and weight gain composition in preterm infants fed FHM and PTF. It was not a randomized study as the feeding regimen was determined by the mother's choice, but it was performed with the aim of evaluating the sensitivity of nutritional studies by use of DXA for the detection of significant differences related to nutritional intervention. Weight gains of 15.9 and 19.9 $\mathrm{g} \cdot \mathrm{kg}^{-1} \cdot \mathrm{d}^{-1}$, respectively, in the FHM and PTF groups are comparable to data reported in similar groups of preterm infants $(8$, $9,24,25)$. The overall weight gain during the period of study was 630 and $913 \mathrm{~g}$ in the two groups, an increase of 42 and $63 \%$ over initial body weight. During the course of a longitudinal study, these values represent twice the minimal estimated weight gain to obtain a significant difference in all the whole body variables in a cohort of 20 infants fed FHM and more than three times the minimal weight gain in a similar cohort of infants fed PTF.

Growth and weight gain composition of the preterm infant during the first weeks of life differ from that of the fetus in utero. From birth to the time of discharge, body weight and body-length growth deviate from intrauterine reference values (20) in the FHM group by -1.04 and $-1.30 \mathrm{SD}$ and in the PTF group by -0.45 and $-1.33 \mathrm{SD}$, respectively. Such a difference has often been reported in very-low-birth-weight infants (26, $27)$ and may lead to a long-term reduction in linear growth $(28$, 29).

We recently reported data on whole body composition obtained using DXA in preterm and term infants soon after birth and showed that the values were similar to intrauterine reference values reported previously using carcass analysis of deceased fetuses and neonates. Compared with those data and relative to body weight, the whole body lean mass and fat mass contents determined in our two groups at the end of the study fell within the reference range (Fig. 1), although the fat mass was significantly higher in infants fed PTF than in those fed FHM.

After birth, the use of the gastrointestinal tract instead of the umbilical cord to provide all nutrients for growth does not change the energy and protein supply necessary for bone growth significantly. However, it causes a large reduction in calcium availability for mineralization and, thus, leads to relative osteopenia characterized by a disproportionate reduction in bone mineral to the extent that the relative amount of unmineralized matrix (osteoid) is increased above normal levels $(18,19,30)$. Our data obtained at the end of the study seem to confirm such an interpretation. Indeed, whereas bone area was in the range of the reference values according to body weight, bone mineral content, both absolute and related to bone area, was significantly decreased. In addition, from the first to the second examination and compared with the reference, there was a significant change in bone mineral content $(-1.9 \mathrm{SD}$ in both groups) and bone mineral content related to bone area $(-2.1 \mathrm{SD})$ in the FHM group and $-2.4 \mathrm{SD}$ in the PTF group, confirming the insufficient postnatal mineral supply and retention in orally fed preterm infants.

At the time of discharge, the sensitivity of our study design for detecting significant differences in whole body composition between two groups of 20 infants ranged from 8 to $31.6 \%$ according to the variable assessed. For fat mass, and considering the relatively low fat-mass content at the time of discharge, the sensitivity appears to be better than could be obtained by other indirect methods (6). Considering that DXA provides an assessment of the whole body in three separate compartments, it appears to be one of the most interesting noninvasive methods presently available for investigating whole body composition in preterm infants.

The weight gain composition determined by DXA was in the range of the values we reported previously using metabolic balance studies and indirect calorimetry in preterm infants fed on similar regimens $(25,31)$. In the present study, dietary intervention was the main determinant of weight gain and whole body composition in preterm infants. As suggested by Cooke et al. (13), sex was an additional significant independent variable, resulting in an increase in fat mass and bone mineral content in female infants (32), but the contribution of this was relatively small compared with the feeding regimen. By use of DXA, the sensitivity for detecting significant differences in weight gain composition appeared to be at least similar to that obtained by more invasive techniques. Between two groups of 20 preterm infants, the sensitivity was approximately $14 \%$ for lean body mass and $27 \%$ for fat mass. The figures for bone area $(18 \%)$ and bone mineral content $(23 \%)$ were intermediate between those values.

Our results relating to bone mineralization need additional comment. Bone growth is related to the protein and energy supply necessary for osteoid matrix synthesis, and growth in bone area in the two groups may reflect the difference in body weight gain. In contrast, bone mineral content has been con- 
sidered to be a measure of the hydroxyapatite content and gain in bone mineral content to be a reflection of mineral accretion. In our validation study, we observed a calcium to bone mineral content ratio of $46.5 \%$, and we reported that the whole body calcium content was accurately measured by DXA with an error of estimation of only $4.4 \%$. Using the same type of conversion equation, the whole body calcium content estimated in preterm and term infants at birth was similar to the intrauterine reference values. In our present study, the lower bone mineral accretion observed in the infants fed FHM suggests that calcium retention was lower in those infants than in the PTF-fed infants $(99 \pm 31$ and $133 \pm 47 \mathrm{mg}$ of calcium per $\mathrm{kg} / \mathrm{d}$, respectively). These values, which are close to the fetal accretion rate, are higher than expected from published calcium intake and metabolic balance studies. Indeed, in preterm infants fed similar human milk fortifier or PTF, a calcium retention of 45 to $60 \mathrm{mg} \cdot \mathrm{kg}^{-1} \cdot \mathrm{d}^{-1}$ was previously obtained (33, 34 ), and similar values were determined in 20 of the preterm infants fed fortified PTF enrolled in this study (our unpublished data). By contrast, the similar reduction in our two study groups in BMDI and bone mineral content related to bone area suggests that the bone mineral content to calcium ratio may be modified after birth by disproportionate bone growth in relation to mineral deposition. These data suggest that when using the infant whole body software, which has a low threshold value for assessing the pixel count of bone, the attenuation coefficient of the matrix could be such that it is erroneously counted as bone, leading to a relative overestimation of bone mineral mass. In our study, the significant difference in accretion of bone mineral content between the two groups disappeared when the data were adjusted for the weight gain difference, suggesting that the effect was largely caused by differences in bone matrix growth rate between the two groups.

\section{CONCLUSIONS}

Our study suggests that DXA is a useful technique for evaluating whole body and weight gain composition in preterm infants. The sensitivity for detecting significant within-group differences in a longitudinal study and between groups in a parallel study depends on the variance of the population and on the various indices assessed but appears to be relatively high, allowing comparison of various feeding regimens in preterm infants during the first weeks of life. However, owing to the low threshold level for bone detection, the bone mineral content measurement does not represent bone mineral mass exclusively and, therefore, cannot be directly converted to calcium content and accretion.

\section{REFERENCES}

1. Lucas A, Gore SM, Cole TG 1984 Multicentral trial on feeding low birth weight infants: effect of diet on early growth. Arch Dis Child 59:722-730.

2. Lucas A 1993 Influence of neonatal nutrition on long-term outcome. In: Salle BL, Swyer PR (eds) Nutrition of the Low Birth Weight Infants. Nestlé Nutrition Workshop Series, Vol 32. Raven, New York, pp 183-196

3. Spady DW, Filipow LJ, Overton TR, Szymanski WA 1986 Measurement of total body potassium in premature infants by means of a whole-body counter. J Pediatr Gastroenterol Nutr 5:750-755
4. Tang W, Modi N, Clark P 1993 Dilution kinetics of $\mathrm{H}_{2}{ }^{18} \mathrm{O}$ for the measurement of total body water in preterm babies in the first week after birth. Arch Dis Child 69:28-31

5. Tang W, Ridout D, Modi N 1997 Assessment of total body water using bioelectrical impedance analysis in neonates receiving intensive care. Arch Dis Child 77:123-126

6. de Bruin NC, van Velthoven KAM, de Ridder M, Stijnen T, Juttmann RE, Degenhart HJ, Visser HKA 1996 Standards for total body fat and fat-free mass in infants. Arch Dis Child 74:386-399

7. Fusch C, Slotboom J, Fuehrer U, Schumacher R, Keisker A, Zimmermann W, Moessinger A, Boesch C, Blum J 1999 Neonatal body composition: dual-energy X-ray absorptiometry, magnetic resonance imaging, and three-dimensional chemical shift imaging versus chemical analysis in piglets. Pediatr Res 46:465-473

8. Putet G, Salle L, Rigo J, Senterre J 1984 Nutrient balance, energy utilization, and composition of weight gain in very-low-birth-weight infants fed pooled human milk or a preterm formula. J Pediatr 105:79-85

9. Putet G, Salle L, Rigo J, Senterre J 1987 Supplementation of pooled human milk with casein hydrolysate: energy and nitrogen balance and weight gain composition in very-low-birth-weight infants. Pediatr Res 21:458-461

10. Picaud JC, Rigo J, Nyamugabo K, Milet J, Senterre J 1996 Evaluation of dual energy $\mathrm{x}$-ray absorptiometry (DXA) for body composition assessment in piglets and term human neonates. Am J Clin Nutr 63:157-163

11. Koo WWK, Walters J, Bush AJ, Chesney RW, Carlson SE 1996 Dual-energy-x-ray absorptiometry studies of bone mineral status in newborn infants. J Bone Min Res 11:997-1002

12. Rigo J, Nyamugabo K, Picaud JC, Gerard P, Pieltain C, De Curtis M 1998 Reference values of body composition obtained by dual energy $\mathrm{x}$-ray absorptiometry in preterm and term neonates. J Pediatr Gastroenterol Nutr 27:184-190

13. Cooke RJ, McCormick K, Griffin IJ, Embleton N, Faulkner K, Wells JC, Rawlings DC 1999 Feeding preterm infants after hospital discharge: effect of diet on body composition. Pediatr Res 46:461-464

14. Faerk J, Petersen S, Petersen B, Michaelsen KF 2000 Diet and bone mineral content at term in premature infants. Pediatr Res 47:148-156

15. Picaud JC, Nyamugabo K, Braillon P, Lapillonne A, Claris O, Delmas P, Delmas P, Meunier P, Salle B, Rigo J 1999 Dual-energy x-ray absorptiometry in small subjects: influence of DXA equipment on assessment of mineralization and body composition in newborn piglets. Pediatr Res 46:772-777

16. Kellie SE 1992 Measurements of bone density with dual energy x-ray absorptiometry (DEXA) for infants. JAMA 267:286-294

17. Molgaard C, Thomsen BL, Prentice A, Cole TJ 1997 Whole-body bone mineral content in healthy children and adolescents. Arch Dis Child 76:9-15

18. Rigo J, De Curtis M, Nyamugabo K, Pieltain C, Gerard P, Senterre J 1998 Premature bone. In: Bonjour JP, Tsang RC (eds) Nutrition and Bone. Nestlé Nutrition Workshop Series, Vol 41. Raven, New York, pp 83-98

19. Rigo J, De Curtis M, Pieltain C, Picaud JC, Salle BL, Senterre J 2000 Bone mineral metabolism in the micropremie. Clin Perinatol 27:147-170

20. Usher R, McLean F 1969 Intrauterine growth of liveborn Caucasian infants at sea level: standard obtained from measurements in 7 dimensions of infants born between 25 and 44 weeks of gestation. J Pediatr 74:901-910

21. Kirkwood BR 1996 Essentials of Medical Statistics. Blackwell, Oxford, pp 196-197

22. Perring J, Cooke RJ, Henderson M, Euler E 1998 A comparison of nutrient accretion using energy balance studies and dual energy x-ray absorptiometry. Pediatr Res 44:452

23. Fusch C, Keisker A, Keller C, Moessinger A 1999 Postnatal changes of body composition in healthy term $v s$. preterm infants. Pediatr Res 45:914A(abstr)

24. Whyte RK, Haslam R, Vlainic C, Shannons S, Samulski K, Campbell D, Bayley HS, Sinclair JC 1983 Energy balance and nitrogen balance in growing low birth-weight infants fed human milk or formula. Pediatr Res 17:891-898.

25. Putet G 1993 Energy. In: Tsang RC, Lucas A, Uauy R, Zlotkin S (eds) Nutritional Needs of the Preterm Infants: Scientific Basis and Practical Guidelines. Williams \& Wilkins, Baltimore, pp 15-28

26. Gill A, Yu VY, Bajuk B, Astbury J 1986 Postnatal growth in infants born before 30 weeks' gestation. Arch Dis Child 61:549-553

27. Hack M, Weissman B, Borawski-Clark E 1996 Catch-up growth during childhood among very low-birth-weight children. Arch Pediatr Adolesc Med 150:1122-1129

28. Ross G, Lipper EG, Auld PAM 1990 Growth achievement of very low birth weight premature children at school age. J Pediatr 117:307-309

29. Rigo J, Boboli H, Franckart G, Pieltain C, De Curtis M 1998 Surveillance de l'ancien prematuré: croissance et nutrition. Arch Pediatr 5:449-453.

30. Reid IR 1996 Bone homeostasis. In: Gluckman PD, Heymann MA (eds) Pediatrics and Perinatology. Arnold, London, pp 552-556

31. Putet G, Picaud JC, Salle L, Rigo J, Senterre J 1993 Utilization and storage of energy. In: Salle BL, Swyer PR (eds) Nutrition of the Low Birth Weight Infants. Nestlé Nutrition Workshop Series, Vol 32. Raven, New York, pp 71-82

32. Pieltain C, De Curtis M, Studzinski F, Rigo J 1999 Gender influence on body composition in preterm infants fed human milk or preterm formula. Pediatr Res 45:913A(abstr)

33. Bronner F, Salle BL, Putet G, Rigo J, Senterre J 1992 Net calcium absorption in premature infants: results of 103 metabolic balance studies. Am J Clin Nutr 56:10371044.

34. Salle BL, Senterre J, Putet G 1993 Calcium, phosphorus, magnesium, and vitamin D requirements in premature infants. In: Salle BL, Swyer PR (eds) Nutrition of the Low Birth Weight Infants. Nestlé Nutrition Workshop Series, Vol 32. Raven, New York, pp 125-135 